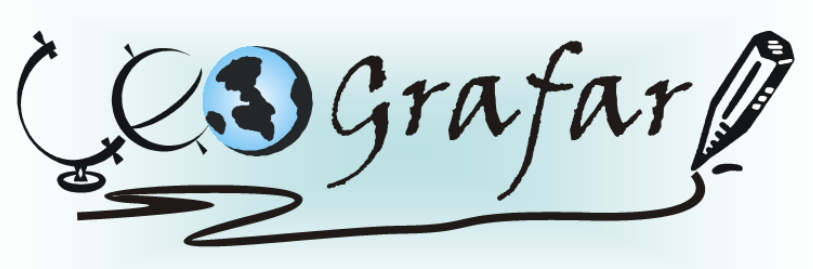

Revista Eletrônica do Programa de Pós-Graduação em Geografia - UFPR

\title{
PRODUÇÃO DO ESPAÇO, VALORIZAÇÃO DIFERENCIAL DO SOLO E DESIGUALDADE SOCIOESPACIAL URBANA EM RIBEIRÃO PRETO-SP ${ }^{1}$
}

\author{
MARCOS ANTÔNIO SILVESTRE GOMES ${ }^{2}$
}

\begin{abstract}
RESUMO
Neste trabalho se considera o espaço produção social, onde muitos agentes, com objetivos diferentes e contraditórios, participam desse processo. Isso reforça a ideia de que esta produção se constitui em um processo conflituoso e desigual, combinando diferentes estratégias e formas de acesso à propriedade privada e apropriação do espaço. De maneira específica, este artigo discute a produção do espaço urbano em Ribeirão Preto-SP, destacando os condicionantes históricos que permitem a compreensão das desigualdades socioespaciais observadas no período atual. Utiliza-se de análises teóricas, levantamentos de dados em órgãos públicos e privados, entrevistas com representantes do poder publico e mercado imobiliário, pesquisas de campo etc., para compreender a complexidade deste processo. Demonstra a valorização diferencial do solo nas diversas parcelas da cidade, entre 1990 e 2008, e a atuação do poder público e mercado imobiliário na consolidação desse processo, sobretudo, na produção do setor Sul como a parcela mais atrativa, mais valorizada e que mais se valoriza na cidade, o que a distingue e aparta socioespacialmente das demais parcelas da cidade.
\end{abstract}

Palavras-chave: produção do espaço urbano, valorização diferencial do solo, Ribeirão Preto.

\footnotetext{
${ }^{1}$ Este artigo é parte das discussões da tese de doutorado do autor, intitulada: Parques urbanos de Ribeirão Preto-SP: na produção do espaço o espetáculo da natureza. Tese orientada pela profa. Dra. Arlete Moysés Rodrigues, defendida em 2009 no IG-UNICAMP.

${ }^{2}$ Professor Adjunto - Universidade Federal Fluminense - Pólo de Campos dos Goytacazes; E-mail: gomesmas@yahoo.com.br
} 


\title{
SPACE PRODUCTION, DIFFERENTIAL VALORIZATION OF SOIL AND URBAN SOCIO-SPATIAL INEQUALITY IN RIBEIRÃO PRETO (SP)
}

\begin{abstract}
In this article, the space of social production is considered, as many agents with different and contradictories aims participate from it, reinforcing the idea that this production consist of a conflicting and unequal process, combining different strategies and forms of access to private property and space appropriation. Specifically, this paper discusses the urban space production in Ribeirão Preto (SP), focusing on the historical conditionings that permit the socio-spatial inequalities comprehension of today. Theoretical analysis, data surveys in public and private divisions, interviews with public power and housing representatives and field research are done to comprehend the complexity of the problem. Shows the differential valorization of the soil all over the various sites of the city between 1990 and 2008, the government and the real estate market actions over the consolidation of this process, chiefly, in the South area production as the most attractive and appraised site, beyond being that whose increase in the economic value is the most, distinguishing and separating it socio and spatially of the other sites of the city.
\end{abstract}

Key words: urban space production, differential valorization of soil, Ribeirão Preto.

\section{INTRODUÇÃO}

Ribeirão Preto, sobretudo a partir da década de 1990, passou por um processo de expansão urbana e efervescência do mercado imobiliário de médio e alto padrão, resultando em uma rápida e induzida ocupação do setor Sul-sudeste ${ }^{3}$ do município, em direção ao Distrito de Bonfim Paulista. Essa expansão é materializada, sobretudo, em forma de loteamentos/condomínios horizontais e verticais, como investimento imobiliário bastante rentável, em especial para as camadas de médio e alto poder aquisitivo.

No processo de expansão para o setor Sul-sudeste, criam-se atrativos para justificar a escolha de investimento. Esses atrativos se revelam em forma de grandes e arborizadas avenidas, áreas de esporte e lazer, sistema de segurança, espaços livres ajardinados como parques, entre outros. Há a seletividade de compradores/moradores, com base no poder aquisitivo, contribuindo para a

\footnotetext{
${ }^{3}$ De acordo com o Decreto Municipal $n^{\circ} 333$, de 26 de dezembro de 1983, a cidade se divide em setores e subsetores, sendo os setores: Norte, Sul, Leste, Oeste e Central.
} 
produção de um espaço diferenciado do ponto de vista urbanístico: edificações amplas e projetos arquitetônicos arrojados.

Esse eixo de crescimento urbano, que se consolida pela presença de condomínios residenciais de luxo, murados ou não, e pela paisagem marcante de um "ambiente esteticamente agradável", contrasta com a periferia pobre que se espraia pelos outros setores da cidade, culminando, ao mesmo tempo, no crescimento dos bairros populares.

O processo de consolidação da ocupação de alto padrão imobiliário em parcelas específicas da cidade, como se destaca nesta análise, tem raízes históricas, pois ao longo da evolução urbana de Ribeirão Preto a população de maior poder aquisitivo ocupa a vertente centro-sul da cidade. Sempre foram concentrados esforços na tentativa de consolidar os bairros que surgiam e mesmo transformar alguns que, tradicionalmente são ocupados por camadas de renda média-baixa, como o Santa Cruz, em bairros "nobres".

Essa tendência não ocorreu simplesmente de forma espontânea. Acredita-se que alguns fatores, como este estudo objetiva demonstrar, contribuíram para essa consolidação.

\section{MÉTODO}

Nesta pesquisa se considera a cidade um espaço privilegiado das manifestações do modo capitalista de produção.

Para Rodrigues (1988), através da concentração da riqueza e disseminação da pobreza, a cidade expressa na desigualdade socioespacial a divisão social e territorial do trabalho. A cidade é o lugar privilegiado da acumulação de capital, da concentração de indústrias, comércio, serviço, equipamentos e meios de consumo coletivo, enfim a cidade concentra a produção e o consumo. Expressa, portanto, as lutas, os conflitos, os antagonismos das classes, as contradições da sociedade e, por conseguinte, da produção, reprodução e do consumo do espaço.

Como salienta Carlos (1994), o espaço é produto, condição e meio do processo de reprodução das relações sociais. Nesse sentido, o debate sobre o espaço urbano deve considerá-lo não somente como condição geral de realização do processo de reprodução do capital, mas também como produto deste processo, 
expressando as contradições que emergem do conflito entre as necessidades do capital, de um lado, e as necessidades da sociedade como um todo, do outro.

Como Gottdiener (1997, p. 28), se considera o espaço construção social em todas as suas manifestações. No entanto, esta construção está relacionada à lógica que domina as relações de produção, ou seja, a lógica capitalista, centrada na materialidade do mundo. Considerando esta perspectiva teórica de análise, o método que fundamenta a pesquisa é o materialismo histórico e dialético que se pauta na investigação das contradições da realidade.

Assim, para esta análise, foi necessário o embasamento teórico em referencial sobre a temática urbana e regional, consultas no acervo do Arquivo Histórico de Ribeirão Preto e em jornais locais, levantamentos e entrevistas em órgãos públicos como secretarias municipais e mercado imobiliário, além de pesquisas de campo.

\section{RESULTADOS E DISCUSSÃO}

\subsection{CONDICIONANTES HISTÓRICOS DA DESIGUALDADE SOCIOESPACIAL URBANA EM RIBEIRÃO PRETO}

Pode-se considerar que o setor Central em Ribeirão Preto, com padrão de construção predominantemente constituído de edifícios verticalizados, de mais de 10 pavimentos, foi a área a partir da qual se deu o direcionamento da expansão urbana no município, culminando no direcionamento do uso do solo e nos padrões de diferenciação urbana, através da implantação de infraestruturas, definição do tamanho dos lotes, tipos de edificações, entre outros (Mapas 1 e 2).

Como afirma Paziani (2007, p. 02),

Ribeirão Preto cresceu no ritmo de elites aventureiras que procuravam introduzir novos elementos urbanos. Do roldão dos milhões de sacas de café negociados entre os grandes coronéis do município - Francisco Schmidt, Artur Diederichsen, Martinho Prado Júnior, Joaquim da Cunha Diniz Junqueira -, o governo federal e estadual e os principais agentes financiadores no exterior - banqueiros e especuladores -, a cidade de Ribeirão Preto atraiu a vinda de (i)migrantes de toda cepa - capomastri e muratori, engenheiros, jardineiros, médicos, advogados e outros profissionais - que participaram da construção da cidade ideal - ou centro -, exemplificado nas primeiras redes de água e esgotos e postes de 
iluminação elétrica (1898-1900)" (grifos do autor).

De acordo com Migliorini (1997), o primeiro projeto de parcelamento do solo nas imediações do núcleo central urbano de Ribeirão Preto foi o Núcleo Colonial Antônio Prado ${ }^{4}$, criado, em 1887, para atender à grande demanda de imigrantes, sobretudo italianos que chegavam ao município para trabalhar na lavoura cafeeira. Esse Núcleo Colonial foi implantado, em sua maior parte, nas áreas correspondentes aos bairros atuais do Ipiranga, Vila Tibério e Campos Elíseos (MAPA 1), sendo composto de inúmeras chácaras e de um subnúcleo urbano ${ }^{5}$, que corresponde a uma parte da atual Vila Tibério. Essas chácaras, mais tarde subdivididas, determinaram a configuração e diferenciação dos tamanhos dos lotes nestes bairros, atendendo primordialmente à classe trabalhadora.

A Vila Tibério constituiu, assim, o início da expansão urbana de Ribeirão Preto, através do Núcleo Colonial Antônio Prado, que abrangia terras do oeste, norte e leste do município. A criação da Vila Industrial, na década de 1910, em função da Cervejaria Antártica, significou a consolidação desse fato porque permitiu a essas áreas a contiguidade do núcleo urbano central, ou Patrimônio da Matriz, pois fazia ligação entre o núcleo original (área central) e o primeiro subnúcleo urbano (Vila Tibério).

\footnotetext{
${ }^{4}$ De acordo com Silva (2007, p. 02), no Brasil, "com o sistema de escravidão ameaçado, a solução para a falta de braços para lavoura havia sido encontrada desde a primeira década do século XIX, com a primeira tentativa do governo imperial na implantação de núcleos coloniais: a estratégia consistia na contratação de trabalhadores assalariados europeus, e a forma de fixá-los ao país seria por meio da distribuição de pequenas propriedades. Os núcleos coloniais desempenhariam a função de 'gérmens' de futuras cidades, uma vez que havia necessidade de povoamento e estruturação social do país, por meio de uma classe média que deveria ser formada por um novo elemento nacional, diferente do negro, seguindo planos do governo imperial para 'embranquecimento' da população brasileira".

5 "Um regulamento aprovado pelo governo imperial desde 1867 estipulava um projeto para os núcleos coloniais. Neste caso, a área foi dividida em duzentos lotes, dispostos em cinco partes, sendo uma delas, com lotes menores - também chamada 'seção urbana', concebida para funcionar como uma administração do núcleo - e quatro seções, formadas por lotes 'rurais', que eram maiores. O valor do metro quadrado dos lotes da sede era dez vezes superior ao valor da mesma área em uma das quatro seções 'rurais', e para adquirir um era necessário que o candidato exercesse algum tipo de ocupação urbana. A criação e administração do núcleo eram de responsabilidade da Inspetoria de Terras e Colonização e da agência Central de Imigração, bem como todo o funcionamento até a quitação da maioria dos lotes, que ocorreu em 1893 - neste momento, o núcleo foi 'emancipado', e sua área foi incorporada ao município"(SILVA, 2007).
} 
Mapa 1 - Ribeirão Preto: Área urbana, de expansão e eixos prioritários de expansão

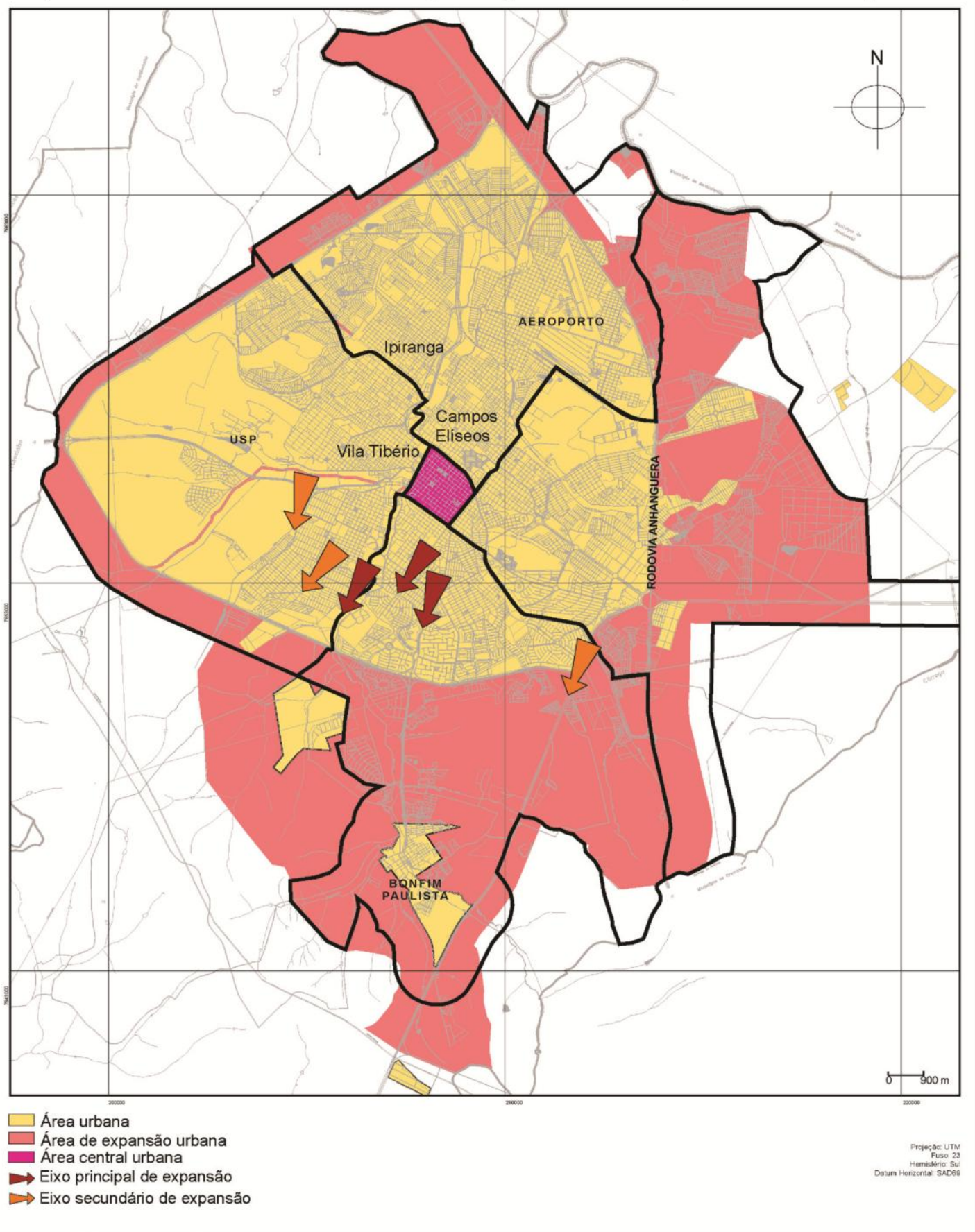

Afirma Migliorini (1997, p. 76) que, com a implantação do Núcleo Colonial Antônio Prado, os loteamentos que iam surgindo na cidade, ao redor da área central, 
acompanharam o sistema de vias ortogonais definidas no projeto do Núcleo.

Em toda a região Norte e Oeste, que envolve especialmente os bairros do Ipiranga e Campos Elíseos, "os processos de parcelamento do solo aconteciam isoladamente, e em áreas muitas vezes equivalentes às das chácaras", que aos poucos foram sendo subdivididas, devido à expansão das atividades urbanas e à necessidade de assentamento urbano dos membros da família proprietária, que crescia com o casamento do filhos ${ }^{6}$ (MIGLIORINI, 1997, p. 76-77).

O Núcleo Colonial Antônio Prado significou a possibilidade de acesso à terra para a parcela dos imigrantes que dispunham de recursos e também permitiu a ascensão social de parte desses trabalhadores que passaram a atuar na cidade, sobretudo, como comerciantes e proprietários de oficinas e fábricas.

A implantação do Núcleo Colonial Antônio Prado caracterizou o início da desigualdade socioespacial em Ribeirão Preto, uma vez que delimitou duas áreas antagônicas, mas complementares, no espaço urbano. De um lado, o núcleo central, ocupado pelas elites, que recebia os melhoramentos públicos necessários à salubridade, higiene e embelezamento da "cidade moderna". Do outro, os bairros das zonas Norte e Oeste, ocupados pelas classes trabalhadoras, onde os investimentos públicos não chegavam e para onde eram direcionados os equipamentos e/ou serviços públicos e privados, tidos como indesejáveis para as classes mais abastadas.

Para Silva (2007), a implantação e/ou remoção de vários equipamentos urbanos para o Núcleo Colonial Antônio Prado, tidos como "indesejáveis" pela elite, já instalada no núcleo urbano central, representou a contribuição direta do poder público ao processo de segregação socioespacial que se delineava. A remoção do Cemitério Municipal, a instalação do hospital de isolamento de leprosos, do cemitério de leprosos, do matadouro municipal, da Santa Casa de Misericórdia, do Asilo Padre Euclides, além de outros equipamentos públicos e privados como albergues, sanatórios, orfanatos e fábricas, constituem exemplos que contrastam com a

\footnotetext{
6 "Inicialmente, os lotes do núcleo colonial funcionavam apenas como chácaras, abastecidas pelos córregos da região, onde os imigrantes produziam milho, arroz, feijão, fubá e criavam animais, utilizando-se da estrada de ferro Mojiana para escoar a produção para outros municípios. A propriedade havia sido adquirida sob condição de cultura e morada efetiva e outras obrigações como: conservação dos marcos dos lotes; construção de residência de pelo menos 'quatrocentos' palmos quadrados'; plantio de 'mil braças quadradas' em até seis meses após a designação do lote; residência de pelo menos um ano antes da obtenção do título definitivo do lote e o pagamento integral antes de sua concessão" (SILVA, 2007).
} 
infraestrutura implantada no núcleo central, especialmente com as medidas sanitaristas adotadas no fim do século XIX.

Segundo Faria (2003, p. 124), o desejo da modernidade, caracterizado pelo controle, pela ordem, pela higiene e pela estética, expresso nos planos de governo e Códigos de Postura, significava o interesse, em especial das elites, na ruptura do ambiente rural e na apartação da pobreza. A chegada da Companhia Mojiana de Estradas de Ferro, em 1883, contribuiu como um símbolo do processo de modernidade a que aspirava a elite. Esse fato também favoreceu a consolidação da "divisão" socioespacial em Ribeirão Preto, que passara a contrastar suas duas faces: "uma intra-rios", moderna, higiênica e embelezada, outra, além-rios, desprovida das melhorias que acompanhavam esse trinômio da cidade burguesa".

Como afirma Silva (2007, p. 07),

uma vez que a cidade se encontrava em expansão e o urbanismo vigente na época afastava da área central os focos de contaminação por doenças, incluindo-se, indiretamente, pessoas que não faziam parte das elites, estas encontraram, na área do núcleo colonial, terras acessíveis para sua moradia.

As distinções impostas territorialmente entre o núcleo central e o periférico, marcadas pelos antagonismos nas suas representações de progresso e atraso, urbano e rural, civilizado e bárbaro, viam-se conflitar no cotidiano. Como salienta Paziani (2007, p. 05),

ao mesmo tempo que alimentava o imaginário de ilustres visitantes e membros da elite cafeeira, a cidade ameaçava romper a ordem e o progresso ao traduzir-se em cenário de conflitos, acidentes, mendicância e prostituição, desmistificando assim a cidade ideal feita de belos edifícios e praças ajardinadas alardeadas pela própria imprensa" (grifos do autor).

Se, por um lado, as localidades ao norte e oeste foram se consolidando como típicos bairros da classe trabalhadora e da classe média, diante do processo de expansão urbana que começara a ocorrer; por outro, as terras ao sul do núcleo central urbano foram, paulatinamente, concentrando as classes mais abastadas, favorecidas com os lucros auferidos com o café.

\footnotetext{
${ }^{7} \mathrm{O}$ termo é geralmente utilizado por pesquisadores para designar, naquele momento histórico, o núcleo central urbano, localizado na confluência da margem direita do Córrego Ribeirão Preto e da margem esquerda do Córrego Retiro Saudoso. Assim, os territórios além-rios são designados como aqueles que representam as classes trabalhadoras, localizados no Núcleo Colonial Antônio Prado.
} 
No período de 1892 a 1935, de acordo com Sanches (2003), intensificaram-se as construções na cidade, com a economia cafeeira, o que provocou mudanças no quadro urbano e, por seu turno, nos instrumentos de atuação urbana e na organização interna da cidade. Nesse período, a Câmara Municipal deixa de ser a única responsável pelo ordenamento urbano, passando a atuar no campo do Legislativo, e é criada a Intendência Municipal, atuando no campo do Executivo.

$\mathrm{Na}$ área central, por concentrar os serviços públicos e privados e a melhor infra-estrutura urbana, como era comum nas cidades, no período, são erguidas as residências mais luxuosas. Não só as famílias tradicionais, mas "os novos ricos buscavam o luxo e esplendor, aquecendo assim a indústria da construção na cidade" (MIGLIORINI, 1997, p. 72).

A partir do núcleo central urbano e, especificamente da Praça XV de Novembro, historicamente foi se direcionando para o sul do município a ocupação das elites locais. Algumas constatações, ainda que insuficientes para explicar, de todo, o processo, podem auxiliar na compreensão da consolidação do eixo centrosul como área de maior interesse imobiliário: infraestrutura como água, energia e pavimentação das ruas, pois era área prioritária dos investimentos públicos; relevo favorável, visto que se eleva suavemente a partir da Praça XV de Novembro; presença de espaços públicos, como as praças da Bandeira, Luís Vaz de Camões e Sete de Setembro; localização da nova igreja "matriz", construída na primeira década do século $\mathrm{XX}$; relativo distanciamento da área comercial e ferroviária; as regiões Norte e Oeste eram tradicionalmente ocupadas pela classe trabalhadora, especialmente de imigrantes estrangeiros; região Leste apresentava relevo mais abrupto.

De acordo com Silva (2007, p. 12),

toda a parte situada a leste do município, embora também tivesse seguido a demanda imobiliária da década de 1950, teve sua valorização provavelmente acentuada após a implantação da rodovia Anhanguera, que contribuiu para a criação de novo vetor de expansão pelo sentido leste, onde se fixou uma classe média. Além disso, permaneceu em mãos de alguns especuladores imobiliários, que as adquiriram enquanto seu valor era baixo. Também pelo fato de não ter permanecido entre herdeiros dos primeiros proprietários, não teve sua área retalhada como as demais seções e por este motivo, praticamente todos os bairros que tiveram origem da quarta seção constituem exatamente os limites dos lotes originais do Núcleo. 
O início da ocupação urbana do eixo sul do município ocorreu, sobretudo, após a década de 1920, com a abertura das avenidas Nove de Julho e Independência, o surgimento de bairros como o Higienópolis, a ampliação de algumas ruas no sentido sul e algumas reformas urbanas nessa área ${ }^{8}$.

Segundo Migliorini (1997, p. 77),

\begin{abstract}
na região Sul da cidade, notadamente a partir da década de quarenta, começaram a se organizar grandes loteamentos destinados às classes mais abastadas, como o Sumaré, e posteriormente, o Alto da Boa Vista. Estes bairros, por sua vez, seguiam os preceitos utilizados por Hausmman na reestruturação de Paris, ou seja: o traçado viário, a estruturação fundiária e a localização de espaços verdes dispostos de forma a garantir a fácil circulação, com ampla utilização de avenidas e praças rotatórias como confluência de vias; a busca da valorização dos eixos viários e das perspectivas urbanas; e a estruturação interna das quadras, buscando a lógica do parcelamento cadastral em áreas generosas, possibilitando assim a venda dos lotes às classes de renda alta e média-alta.
\end{abstract}

Consolidou-se, na cidade, com a abertura desses loteamentos e da Avenida Nove de Julho, a tendência de ocupação das classes mais abastadas, inicialmente através da construção de inúmeros casarões, além do quadrilátero central. Essa tendência de expansão foi seguindo, no decorrer do século, atingindo áreas cada vez mais afastadas, até mesmo transformando em solo urbano parcelas de terras rurais que interessavam à reprodução do capital, das elites.

Até a década de 1970, devido às poucas leis que tratavam da regulamentação do uso e ocupação do solo urbano, a cidade cresceu, praticamente, ao labor dos investimentos imobiliários, fato que contribuía para a especulação de algumas áreas, especialmente as localizadas na vertente sul.

\footnotetext{
8 "Contam os historiadores, que fato de notável importância foi a chegada do Sr. Álvaro Costa Couto em 1922, responsável pela expansão dos limites da cidade (para o setor Sul), que então terminava na Praça Luiz de Camões, retirando a porteira que fechava a Avenida Nove de Julho, abrindo parte da antiga pedreira, iniciando a Rua João Penteado e ali construindo as primeiras casas. $\mathrm{Na}$ área entre a Rua Bernardino de Campos e a Avenida Nove de Julho e as ruas Álvares Cabral (que permaneceu fechada até 1955...) e Rui Barbosa, construiu os primeiros edifícios de apartamentos no alto da cidade. Com a remoção das máquinas da pedreira, deu segmento à Rua Amador Bueno e abriu a Avenida Santa Luzia, e mais tarde as ruas Eliseu Guilherme, Altino Arantes e Afonso Celso, ligando as Vilas Santa Terezinha e Virgínia. Foi também este senhor que, a partir da década de 30, passou a contratar os arquitetos modernistas, que chegavam à cidade após concluir seus estudos em São Paulo, para o projeto dos seus imóveis" (MIGLIORINI, 1997, p. 72-73).
} 


\subsection{O "PRODUTO ZONA SUL" E A VALORIZAÇÃO DIFERENCIAL DO SOLO URBANO EM RIBEIRÃO PRETO APÓS A DÉCADA DE 1990}

Especialmente a partir da década de 1990, se constata em Ribeirão Preto a abertura de novos loteamentos e condomínios de luxo, no setor Sul da cidade, voltados às classes mais abastadas. Nesse processo, foi criado todo um aparato em infraestrutura: avenidas arborizadas, praças bem equipadas, shopping centers, serviços especializados, parques públicos, entre outros. Todos esses elementos constituíram-se em aparatos públicos e privados para a valorização imobiliária neste setor, em detrimento dos demais setores urbanos ${ }^{9}$ (ver Mapa 2).

Para o então chefe do Departamento de Urbanismo de Ribeirão Preto, José Anibal Laguna, o município é fisicamente maior na parte sul e, por isso, a expansão urbana está se dando naquele sentido. "Além disso, é um local mais alto, com clima mais ameno e, pela valorização imobiliária, tem tendência a se elitizar, virou um sonho de consumo" (BONFIM..., 2006, p. 24).

O discurso empreendido pelo representante do poder público não evidencia a problemática que condiciona um intenso processo de segregação, como se morar fosse uma mera opção e não uma das necessidades básicas de todos (RODRIGUES, 1988). Onde morar pode até ser uma opção, mas está diretamente relacionada com a capacidade de cada um de se inserir no mercado imobiliário. Também, nesse processo, é importante considerar, como afirma Gottdiener (1997, p. 174), que

as necessidades contenciosas de grupos de consumo e os estilos de vida conflitantes dentro de territórios localizados suscitam problemas que não podem ser solucionados apenas por considerações econômicas, mas que também chamam a atenção para questões fundamentais de cultura.

Assim, a escolha de morar na zona Sul não pode ser justificada simplesmente pelas características naturais do local, pela altitude elevada no contexto do sítio urbano e pelas amenidades climáticas diante das elevadas temperaturas típicas da cidade. É necessário considerar que a zona Sul, com todas as suas características naturais e infraestruturais, é uma construção histórica. Tornando-se um "sonho", poucos conseguem a sua realização, porque depende da condição de pagar de cada indivíduo.

\footnotetext{
${ }^{9}$ Para maior aprofundamento, veja-se GOMES (2009).
} 
Dezenas de condomínios residenciais, horizontais ou verticalizados, surgiram nos últimos anos na zona Sul do município, valorizando as áreas que foram deixadas vazias como reserva de valor e os imóveis do Distrito de Bonfim Paulista, que está se conurbando com a área já consolidada no centro. Somente entre os anos de 1990 e 2004, 56 condomínios foram aprovados em Ribeirão Preto, de acordo com a Prefeitura Municipal ${ }^{10}$.

O setor Sul acentuou a concentração dos investimentos de grandes grupos imobiliários, que passaram a lançar, em números cada vez maiores, projetos voltados ao consumidor de média e alta renda. Junto a esses projetos, desenvolveram estratégias para aumentar o potencial de valorização, como a criação de parques, áreas verdes, boulevards, centros de serviços especializados, entre outros.

A partir da década de 1990, ocorreram transformações profundas nesta área, e investimentos de capital ampliaram a implantação de bairros de luxo, condomínios de casas de alto padrão, torres de edifícios de grande magnitude, promovendo maior concentração e dinamização do setor de serviços.

Neste período, do total de condomínios e loteamentos aprovados em Ribeirão Preto, cerca de $70 \%$ foram implantados na zona Sul, contra, aproximadamente, $20 \%$ da zona Leste e $10 \%$ das zonas Norte e Oeste (MAPA 2) ${ }^{11}$. A expansão, seguindo o eixo da Avenida Presidente Vargas até o Distrito de Bonfim Paulista, foi acompanhada da implantação de inúmeros condomínios fechados de casas de médio e alto padrão e dezenas de condomínios verticalizados.

\footnotetext{
${ }^{10}$ Pode-se observar no Mapa 1 a indicação dos eixos de expansão urbana definidos no Plano Diretor Municipal $^{10}$, apontando a zona Sul como o eixo principal.

${ }_{11}$ Embora apareçam manchas expressivas nas zonas Norte, Oeste e Leste se comparadas à zona Sul, isto não significa que houve um aumento no número de loteamentos e condomínios na mesma proporção. Na zona Sul, esse crescimento foi imensamente mais expressivo, em números absolutos. Cada uma das manchas no mapa pode indicar mais de um loteamento e/ou condomínio, agregados pela pequena dimensão, a exemplo dos condomínios verticalizados.
} 


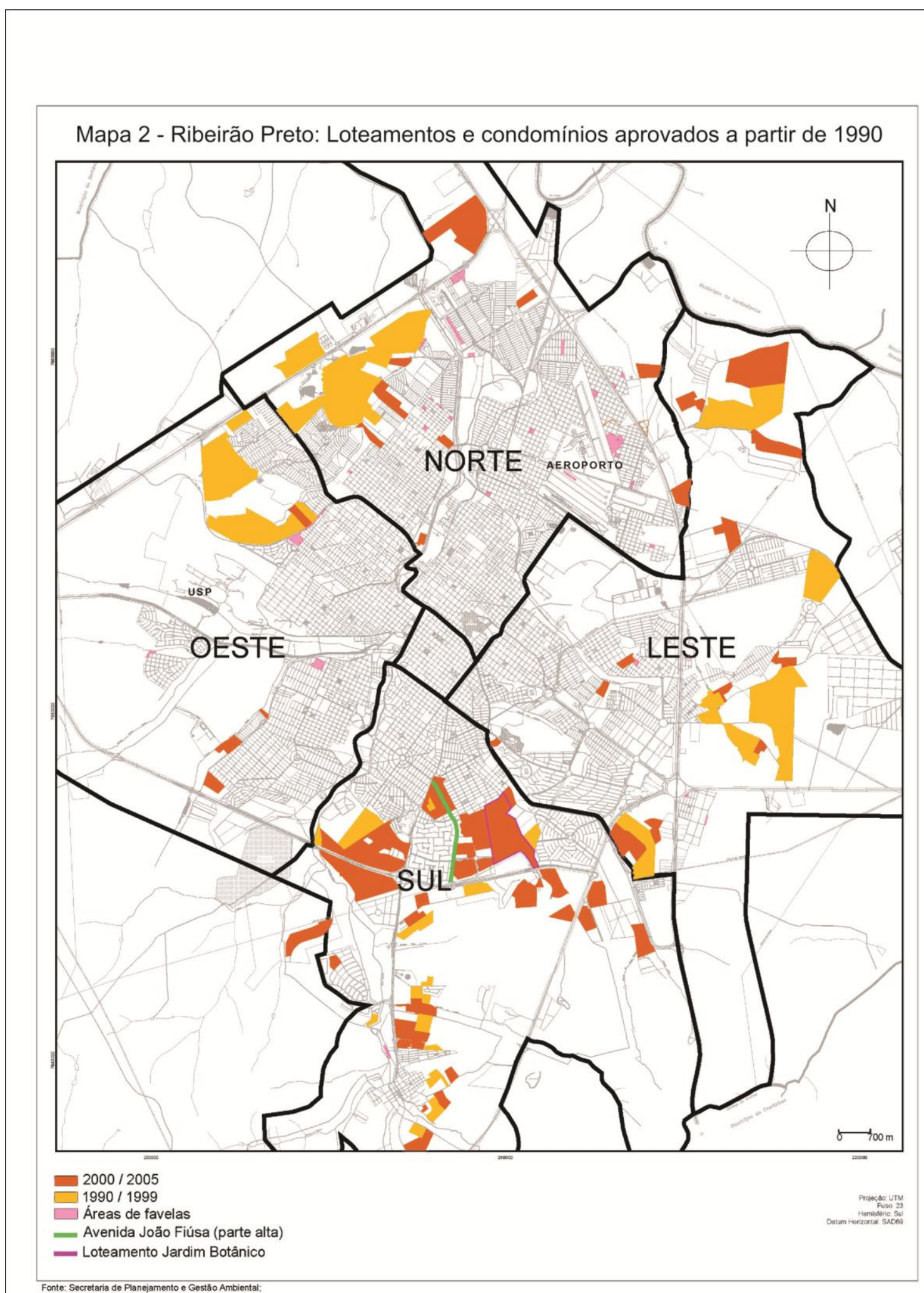

Fonte: Secretaria de Planejamento e Geståo Ambiental;
Org. Freitas: Gomes (2008).

As tabelas 1 e 2 demonstram o preço do solo por $\mathrm{m}^{2}$ nos diferentes setores da cidade (entre 1998 e 2007/2008) e nos condomínios fechados (2007). Evidencia-se os preços mais elevados na zona Sul e, consequentemente, nos condomínios 
fechados por se constituírem em produtos imobiliários que agregam alguns serviços e/ou trabalho realizado.

\section{TABELA 1 - RIBEIRÃO PRETO-SP - PREÇO DO SOLO ${ }^{12}$ POR $\mathrm{M}^{2}$ NA ÁREA URBANA, EM REAIS (R\$)}

\begin{tabular}{|c|c|c|c|}
\hline \multicolumn{4}{|c|}{ Setor Sul } \\
\hline Bairro & 1995 & 1998 & $2007 / 2008^{13}$ \\
\hline Alto da Boa Vista & 102,02 & 122,67 & 300,00 \\
\hline Jardim Califórnia & 82,98 & & 244,00 \\
\hline Jardim Canadá & 61,38 & 73,81 & 180,50 \\
\hline City Ribeirão & 58,83 & 70,74 & 173,00 \\
\hline Jardim Irajá & & 135,76 & 332,00 \\
\hline Jardim São Luiz & 117,32 & & 345,00 \\
\hline Jardim Botânico & & & 260,00 \\
\hline Jardim Nova Aliança & & & 250,00 \\
\hline Jardim Nova Aliança Sul & & & 263,00 \\
\hline \multicolumn{4}{|c|}{ Setor Leste } \\
\hline Lagoinha & 75,84 & 91,19 & 223,00 \\
\hline Ribeirânea & 56,11 & & 165,00 \\
\hline Parque dos Lagos & & & 126,50 \\
\hline Cândido Portinari & & & 79,00 \\
\hline Parque São Sebastião & 17,85 & & 52,50 \\
\hline Ribeirão Verde & & & 106,00 \\
\hline Jardim Novo Mundo & & 44,98 & 110,00 \\
\hline \multicolumn{4}{|c|}{ Setor Oeste } \\
\hline Jardim Piratininga & 27,21 & 32,71 & 80,00 \\
\hline Parque Ribeirão Preto & 30,61 & & 90,00 \\
\hline Ipiranga & 34,01 & & 100,00 \\
\hline Planalto Verde & 34,01 & & 100,00 \\
\hline Jardim Centenário & 27,21 & & 80,00 \\
\hline Jardim Recreio & & & 108,00 \\
\hline Jardim Antártica & & & 242,00 \\
\hline \multicolumn{4}{|c|}{ Setor Norte } \\
\hline Tanquinho & 27,21 & & 80,00 \\
\hline Avelino Palma & 34,01 & & 100,00 \\
\hline Vila Elisa & 37,75 & & 111,00 \\
\hline
\end{tabular}

12 Dada a dificuldade de se detectar com clareza o preço do solo urbano, os valores expressos na tabela são aproximações de mercado, com base nas fontes pesquisadas. Os dados de $1995 \mathrm{e}$ 2007/2008 foram retirados de anúncios de preços de terrenos, no Jornal A cidade, de 5/11/1995 e 17/2/2008, respectivamente, na Imobiliária Pirâmide (Disponível: http://www.piramidimoveis.com.br, acesso em abril de 2008) e na Dínamo Imóveis Administração Ltda (Disponível: http://dinamoimoveis.com.br, acesso em abril de 2008). Os dados de 1998 foram obtidos através de levantamento realizado pela Divisão de Informações de Uso e Ocupação do Solo, da Prefeitura Municipal de Ribeirão Preto, com base em jornais. Os valores obtidos nas fontes foram deflacionados utilizando o INCC (Índice Nacional de Custo da Construção), com base na fórmula de cálculo indicada pela FGV (Fundação Getúlio Vargas). Para aprofundamento sobre este índice, veja-se http://www.fgv.br/dgd/asp/dsp_igp.asp

${ }^{13}$ Considera-se 2007/2008 porque o mês de fevereiro se apresenta na interface da mudança de ano, podendo o preço do solo ter alteração significativa até o final de 2008. Ademais, estabeleceu-se como o marco temporal de análise desta pesquisa o ano de 2007. 


\begin{tabular}{|l|l|l|l|}
\hline Heitor Rigon & & 24,53 & 60,00 \\
\hline Campos Elíseos & & 64,61 & 158,00 \\
\hline Vila Carvalho & 35,58 & 87,00 \\
\hline Jardim Salgado Filho & 16,36 & 40,00 \\
\hline Jardim Aeroporto & 16,36 & 40,00 \\
\hline
\end{tabular}

FONTE: Jornal A Cidade, Ribeirão Preto; Pirâmide Imobiliária, Ribeirão Preto; Secretaria de Planejamento e Gestão Ambiental de Ribeirão Preto - Divisão de Informações de uso e ocupação do solo. Org. O autor (2009).

TABELA 2 - RIBEIRÃO PRETO-SP: PREÇO DO SOLO EM CONDOMÍNIOS - 2007

\begin{tabular}{|l|c|c|}
\hline \multicolumn{1}{|c|}{ Condomínio } & Preço, em $\mathrm{R} \$ / \mathrm{m}^{2}$ & Tamanho dos lotes $\left(\mathrm{m}^{2}\right)$ \\
\hline Arara Verde & 240,00 & 550 a 870 \\
\hline Aspen & 248,00 a 345,00 & 925 a 2.200 \\
\hline Buritis & 290 & 1.005 a 1.255 \\
\hline Monterrey Condo Park & $1.000,00$ & 476 \\
\hline Carmel Condo Park & $1.000,00$ & 987 \\
\hline Village Monet & 500,00 & 1.015 a 1259 \\
\hline Torino & 360,00 & 450 a 550 \\
\hline Verona & 400,00 & 549 a 778 \\
\hline Vila de Buenos Aires & 290,00 & 487 a 560 \\
\hline Milano & 400,00 & 835 a 1.327 \\
\hline Country Village & 500,00 & 778 a 2.134 \\
\hline Das Magnólias & 400,00 & 504 \\
\hline Dos Manacás & 400,00 & 560 a 770 \\
\hline
\end{tabular}

FONTE: Jornal Gazeta de Ribeirão, Especial - Condomínios Horizontais e Verticais, 28 de outubro de 2007. Org. Marcos Antônio Silvestre Gomes. Org.: O autor (2009).

A zona Sul de Ribeirão Preto concentra, além dos terrenos mais caros da cidade, os imóveis que mais se valorizam. Em condomínios como o Colina Verde, o metro quadrado do solo chega a custar 5 mil reais, e uma casa pode atingir 4 milhões de reais. Na Avenida João Fiúza ${ }^{14}$ (Ver Mapa 2), apartamentos de cobertura, como no Edifício Place des Vogues, custam até 3,5 milhões, exemplos que demonstram a forte especulação e a supervalorização a que foi submetida esta zona ao longo dos últimos quinze anos, sobretudo. Ressalte-se que nos preços dos imóveis tem grande importância a qualidade do material empregado na construção, e não somente a localização ${ }^{15}$.

\footnotetext{
${ }^{14}$ Esta avenida concentra grandes edifícios de luxo. Seu projeto de expansão e verticalização foi originado da fusão de interesses e capitais de quatro grupos imobiliários locais: Habiarte Barc, Copema, Stéfani Nogueira e Conspace, que redundou na criação do Grupo de Desenvolvimento Urbano - GDU Incorporações e Construções. Este grupo passou a ter um papel fundamental na expansão da zona Sul, adquirindo terrenos, lançando loteamentos, condomínios e favorecendo a especulação cada vez maior na região, sobretudo a partir de meados da década de 1990, como demonstrou Gomes (2009).
}

${ }^{15}$ Analisar preços de imóveis edificados é uma tarefa que foge ao escopo deste trabalho. 
Em relação ao preço do solo em condomínios ${ }^{16}$, observa-se que há uma variação muito grande, conforme a Tabela 2. Entretanto, a maior parte dos condomínios apresenta o $\mathrm{m}^{2}$ do solo entre $\mathrm{R} \$ 300,00$ e $\mathrm{R} \$ 1.000,00$, com lotes, em geral, acima de $500 \mathrm{~m}^{2}$, resultando em terrenos que podem custar até 1 milhão de reais, como no Condomínio Carmel Condo Park. O tamanho dos lotes nestes condomínios dá uma ideia da expansão horizontal que ocorre na zona Sul.

Segundo Paulo Tadeu Rivalta de Barros, diretor da Habiarte Barc, empresa imobiliária de tradição em investimentos de alto padrão, a zona Sul "está se constituindo em um vetor de alto padrão urbanístico, de alta qualidade imobiliária e com uma alta qualidade no nível de moradias, com áreas verdes imensas, bosques, fundos de vale" (AVENIDA..., 2006, p. 08). Esta empresa divulgou o lançamento, em 2008, do parcelamento da antiga fazenda Olhos d'água, com abertura de condomínios fechados e edifícios verticalizados de alto padrão. No projeto estava prevista a criação de um parque linear, de cerca de $1.500 \mathrm{~m}^{2}$, ao longo do Córrego Olhos d'água, em parceria com a Prefeitura Municipal. Este parque, como outros analisados por Gomes (2009) ${ }^{17}$, evidencia uma das estratégias empreendidas pela parceria público-privada na valorização desigual do espaço urbano.

$\mathrm{Na}$ zona Oeste, cujas terras da antiga fazenda Baixadão estão sendo loteadas por um consórcio de capitais locais, paulistanos e norte-americanos, está aprovada a implantação do Parque "Fazenda Baixadão", com cerca de $500 \mathrm{mil} \mathrm{m}^{2}$, ao longo do Córrego dos Campos $^{18}$. O parque será implantado através de uma parceria público-privada e estará localizado na mais recente área de expansão, que os empreendedores apostam que se transformará na mais "nobre" da cidade.

Torna-se claro que a criação de parques públicos e/ou áreas com atrativos "naturais", na cidade, está atrelada aos interesses especulativos do capital privado,

\footnotetext{
${ }^{16}$ Considera-se ainda, nesta análise, o fato de que nos condomínios, ao contrário dos loteamentos comuns, houve trabalho realizado na terra (projetos, aberturas de vias, tratamentos paisagísticos etc.), o que aponta para a distinção do seu preço em relação aos outros loteamentos.

${ }^{17}$ Este autor analisou, em específico, os processos de criação e implantação dos parques Prefeito Luiz Roberto Jábali e Luís Carlos Raya e suas relações com o processo de valorização fundiária. Destaca que os parques proporcionam renda diferencial no espaço urbano e funcionam como atrativos na zona Sul, contribuindo para o aprofundamento das desigualdades socioespaciais em Ribeirão Preto.

${ }^{18}$ Como ainda não havia sido criado por lei até a data da pesquisa de campo, o parque foi anunciado pela Secretaria de Planejamento e Gestão Ambiental com o nome da antiga fazenda onde será instalado. Segundo o secretário Marcos Spínola de Castro, o projeto já dispunha de seiscentos mil reais, doados pela iniciativa privada, mas não foi declarado o valor total das obras do parque. (Confirmações dadas em entrevista realizada em 14/2/2008).
} 
com investimentos no setor imobiliário, tendo como veículo condutor das estratégias de marketing, ou atrativo de vendas, a produção e oferta da natureza, materializada, sobretudo, sob a forma de parque.

Como diz Harvey (1998, p. 80-81):

A ênfase dos ricos no consumo levou, no entanto, a uma ênfase muito maior na diferenciação de produtos no projeto urbano. Ao explorarem os domínios dos gostos e preferências estéticas diferenciados [...], os arquitetos e planejadores urbanos reenfatizaram um forte aspecto da acumulação de capital: a produção e consumo do que Bourdieu $(1977 ; 1984)$ chama de 'capital simbólico', que pode ser definido como 'o acúmulo de bens de consumo suntuosos que atestam o gosto e a distinção de quem os possui'. Esse capital se transforma, com efeito, em capital-dinheiro, que 'produz seu efeito próprio quando, e somente quando, oculta o fato de se originar em formas 'materiais' de capital. $\mathrm{O}$ fetichismo (a preocupação direta com aparências superficiais que ocultam significados subjacentes) é evidente, mas serve aqui para ocultar deliberadamente, através dos domínios da cultura e do gosto, a base real das distinções econômicas.

$\mathrm{Na}$ lógica capitalista da propriedade privada da terra, da cidade, os equipamentos públicos e privados se inserem no espaço urbano relacionados a estilos arquitetônicos diferenciados e diversificados. São implantados de acordo com os interesses públicos e privados, segundo suas estratégias de ação que, muitas vezes, se conjugam com o objetivo de aumentar rendas, lucros e juros e influenciar um mercado possível a aquisição de padrões de vida, como se constatou em Ribeirão Preto.

\section{CONCLUSÃO}

Este trabalho teve o intuito de analisar a produção do espaço e as desigualdades socioespaciais urbanas em Ribeirão Preto. Como demonstrado, agentes públicos e privados historicamente criaram as condições para 0 desencadeamento, aprofundamento e consolidação das desigualdades socioespaciais urbanas. De um lado, pela canalização maior dos investimentos públicos em infra-estrutura, especificidades nos padrões de uso e ocupação do solo, em especial na vertente centro-sul-sudeste. De outro, pelas estratégias de mercado, sobretudo do segmento imobiliário na criação de produtos diferenciados para o consumidor de alta renda, como os condomínios fechados, torres de apartamentos 
de luxo, shopping centers, lojas de serviços especializados etc.

A zona Sul constitui-se, assim, na parcela do espaço urbano mais valorizada. Concentra tanto a maior parte dos serviços quanto os terrenos e imóveis mais caros e os que mais se valorizam.

Como demonstrado por Gomes (2005), a maioria dos espaços públicos, cuja infraestrutura permite o uso efetivo, está localizada na área central e zona SulSudeste, a exemplo dos parques públicos. Também nessa região, como apontado por Souza (2005), concentram-se os diversos atrativos de lazer e entretenimento urbano, além dos equipamentos voltados ao funcionamento do turismo de negócios e eventos na cidade.

Quando se analisa a espacialização da renda, constata-se que há uma concentração das rendas mais elevadas nas zonas Sul e Leste, o que evidencia uma contradição entre a implantação de equipamentos públicos nessas áreas e a carência desses equipamentos nas zonas Norte e Oeste, concentradoras da população de menor poder aquisitivo (GOMES, 2009).

Enfim, este estudo aponta que há uma atuação marcante e decisiva do poder público municipal no processo de produção desigual do espaço urbano, em consonância com os interesses do mercado imobiliário. Ao tempo em que concentra os investimentos em infraestrutura em parcelas específicas do espaço urbano, contribui para o aumento das desigualdades socioespaciais. Esta atuação nos setores onde se localizam os interesses imobiliários, dirigidos às camadas de mais alta renda da cidade, contribui para o aumento do preço dos terrenos, loteamentos e edificações, consolidando o eixo sul de Ribeirão Preto como uma área estrategicamente rendosa do ponto de vista imobiliário.

\section{REFERÊNCIAS}

AVENIDA de R\$ 1 bi. Gazeta de Ribeirão. Ribeirão Preto, 19 de março de 2006.

BONFIM em alta. Gazeta de Ribeirão. Ribeirão Preto, 8 de junho de 2006, p. 24.

CARLOS, A. F. A. A (re)produção do espaço urbano. São Paulo: Edusp, 1994.

FARIA, R. S. Ribeirão Preto, uma cidade em construção (1895-1930): o moderno 
discurso da higiene, beleza e disciplina. Dissertação (Mestrado). Universidade Estadual de Campinas. Campinas, 2003.

GOMES, M. A. S. As praças de Ribeirão Preto-SP: uma contribuição geográfica ao planejamento e à gestão dos espaços públicos. Dissertação (Mestrado em Geografia). Universidade Federal de Uberlândia. Uberlândia, 2005.

Parques urbanos de Ribeirão Preto-SP: Na produção do espaço, o espetáculo da natureza. Tese (Doutorado em Geografia). Universidade Estadual de Campinas: IGE. São Paulo, 2009.

GOTTDIENER, M. A produção social do espaço urbano. $2^{a}$ edição. São Paulo: Edusp, 1997.

HARVEY, D. A condição pós-moderna: uma pesquisa sobre as origens da

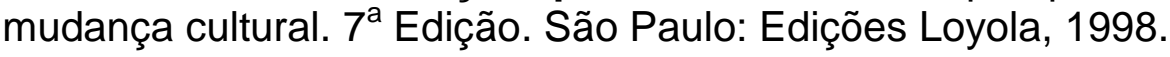

MIGLIORINI, V. L. B. Padrões de desempenho do uso e ocupação do solo na previsão e controle do adensamento de áreas intra-urbanas. Tese (Doutorado em Engenharia de Construção Civil e Urbana). Universidade de São Paulo: Escola Politécnica/USP. São Paulo, 1997.

PAZIANI, R. R. Cultura cafeeira, cultura urbana: as imagens do progresso e as ambiguidades da modernização em Ribeirão Preto na Primeira República. Disponível:

http://www.anpuh.uepg.br/xxiiisimposio/anais/textos/RODRIGO\%20RIBEIRO\%20PA ZIANI.pdf. Acesso: novembro de 2007.

RODRIGUES, A. M. Na procura do lugar o encontro da identidade: um estudo do processo de ocupação de terras: Osasco. Tese (Doutorado em Geografia). Universidade de São Paulo: FFLCH/USP. São Paulo, 1988.

SANCHES, K. A construção da legislação urbanística de Ribeirão Preto: 1874 a 1935. Dissertação (Mestrado em Arquitetura e Urbanismo) - Universidade de São Carlos. São Carlos, 2003.

SILVA, A. C. B. Expansão urbana e segregação social: efeitos da implantação de um núcleo colonial em Ribeirão Preto. Disponível: http://www.anppas.org.br/encontro_anual/encontro2/GT/GT14/adriana_capretz.pdf. Acesso: novembro de 2007.

SOUZA, A. A. Os negócios do turismo no município de Ribeirão Preto: reflexões sobre a produção de cartas temáticas turísticas com o uso do software Arcview. Dissertação (Mestrado em Geografia). Universidade Federal de Uberlândia. Uberlândia, 2005. 